best size is about $11 / 4$ inches in diameter and as thick as a good quality visiting-card. Such a saw can be furnished by any good saw sharpener at a very small cost. It is not necessary to nickel-plate these instruments if they are properly dried after operations. Dull instruments may be resharpened by being immersed in dilute nitric acid until the edges are restored. With such a machine it is very easy to sever bone with a straight or curved cut. cut out all manners of grafts or slots in bone cleanly and quickly, clean out hard, eburnated osteomyelitis cavities, ream out marrow cavities, cut through ankylosed joints, freshen up ends of old ununited fractures, drill holes for nails and screws, trephine the spine or skull, or cut off exostoses. The cuts are remarkably clean and sharp and there is no splintering or chipping of bone as when a gouge or chisel is used.

821 Schofield Building.

INSTRUMENTS FOR THE MANUFACTURE OF AUTOGENOUS BONE NAILS, PEGS AND GRAFTS

Hugh H. Trout, M.D., and R. L. Rhodes, M.D., Roanoke, VA.

In the accompanying illustration 1,2 and 3 represent twistdrills of three sizes and the corresponding reamers for the manufacture of bone nails; 4 is a chuck to receive the drills, and 5 the spindle which receives not only the chuck but the

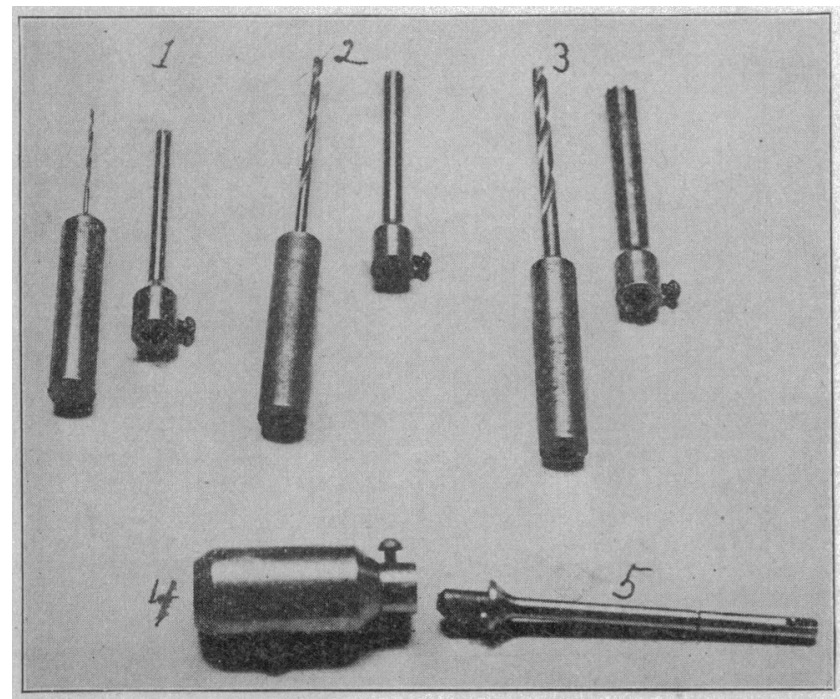

Instruments for the manufacture of autogenous bone nails, pegs and grafts: 1,2 and 3 , twist+drills of three sizes and the corresponding reamers for the manufacture of bone nails; 4 , chuck to receive drills; 5 , spindle which receives chuck and reamer.

reamer as well. These reamers have a slightly wider diameter on the inner side at the base than they have at the cutting end; preventing any binding or twisting of the nail. In obtaining the nails it is advisable to utilize the bones removed from the groove, or at least to make them in the long diameter of the bone if no groove is made. When made in this manner the nail is far stronger than when made trangversely.

Of course, these instruments are operated by means of an electric motor and we find one with a friction-driven shaft less apt to bind and more even in action.

We have now employed these nails, both as intramedullary pegs and as a means of holding bone-grafts in position, in a sufficient number of fracture cases to appreciate their great value.

\section{APPARATUS FOR ENDOSCOPIC GALVANO-CAUTERY OPERATIONS ON THE VESICAL ORIFICE}

\section{H. MoClure Young, A.B., M.D., St. Louis}

Assistant Surgeon to Outpatients, Washington University Medical School

This apparatus is intended primarily for operations on the moderately hypertrophied prostate. It consists of a Braasch direct-vision cystoscope for which operating windows with a hole for the introduction of the cauteries have been made for me by the manufacturers. These cauteries I have had made in two forms, the cautery knife and the cautery curet. As the electrode does not readily pass through the hole in the operating window, a separate window has to be provided for each cautery. These cauteries are to be used under water and, therefore, certain special precautions have to be observed in their manufacture. They must be absolutely impervious to water. If the slightest trace of moisture leaks into them it will cause a short circuit. The distal end requires very particular attention. It must be sealed in a manner to render

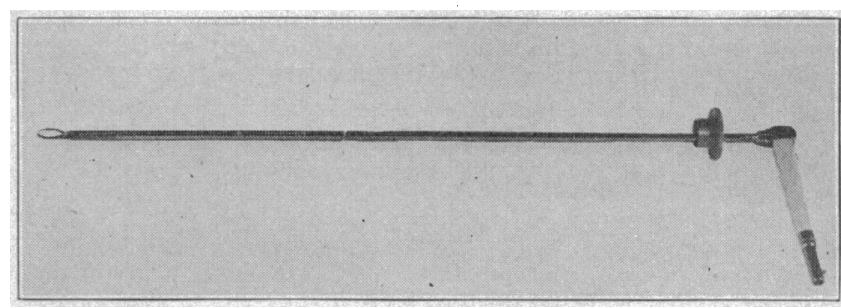

Fig. 1.-The cautery curet

the instrument absolutely water-proof. An ordinary cement will not do, for it is porous. My electrician encases the inner electrode in fine rubbing tubing. Each cautery must be carefully tested before use.

The surgeon having previously determined that his case is one suited to this technic, will introduce his Braasch cystoscope as for an ordinary cystoscopy. No preliminary washing of the bladder is necessary. Having found offending protuberances on middle or lateral lobes, he will introduce his cautery curet, which, of course, has been carefully tested beforehand and his transformer set at exactly the point necessary to heat it properly. The irrigating fluid is permitted to flow through the eystoseope, and the curet is placed firmly against the tissues which it is desired to remove. The current is now turned on and a ribbon of tissue, corresponding to the size of the curet, is cut out. As this ribbon of tissue ordinarily adheres to the curet, it may be removed, the instrument reinserted and the maneuver repeated. This may be continued indefinitely. Bleeding cannot interfere with the vision for the reason that the irrigation carries all blood and debris back to the bladder, thus providing the surgeon always with a clear field. This cystoscope is also an excellent urethroscope for the posterior urethra, and the surgeon can therefore prolong his operations as far forward into the prostatic urethra as he may elect.

The knife, it will be observed, is straight instead of having the conventional downward curve of many prostatic incisors. I believe that when used through the cystoscope a straight knife is preferable for the reason that the point can be kept constantly in view. It will of course cut through the floor of the prostatic urethra just as well as a curved knife could, for the urethra will tend to resume its natural curve as the cystoscope is withdrawn, and this will bring the pros. tate firmly up against the knife. Fairly deep incisions can also be made laterally by deflecting slightly the beak of the instrument.

It is believed that this technic has a somewhat wider field of usefulness than any of the various conservative methods of

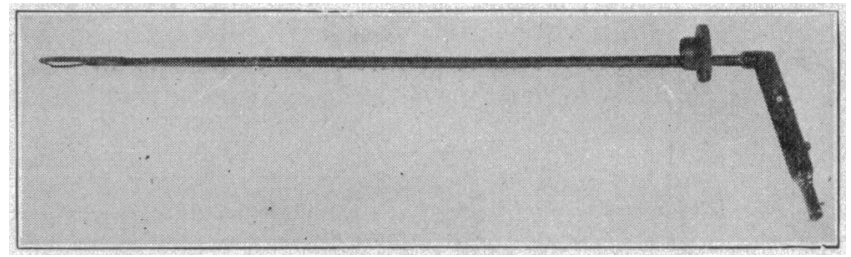

Fig. 2.-The cautery knife.

operating on the prostate hitherto proposed. It has the advantage over the Bottini operation that it can be done under the direct control of the eye. I believe that it is superior to Goldschmidt's procedure also, for the reason that portions of the gland can actually be removed and a more extensive operation performed, and it is much simpler in point of technic. It also would appear to promise somewhat more than the varicus punch operations, for the reason that the surgeon can Incise or excise as he chooses and as deeply as he chooses, can 
review his work almost indefinitely until he is entirely satisfied with the situation he has created, and is not annoyed by the hemorrhage. The only technical difficulty connected with the procedure lies in the proper heating of the cauteries under water, a thing which, however, is entirely feasible and has bcen done many times before. It will require some care in their manufacture and then considerable patience on the part of the surgeon to determine just how much current is necessary to heat them without the danger of fusing them. They must

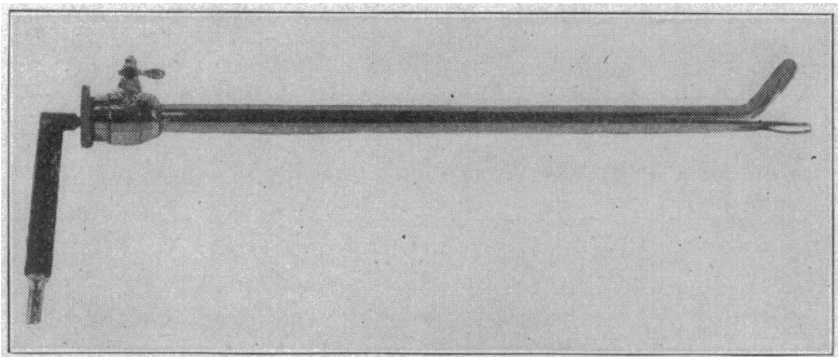

Fig. 3.-Braasch cystoscope with cautery knife in position.

of course never be exposed to the current while in the air or they will fuse instantly. At best the surgeon must expect to burn out a knife occasionally and should therefore always take several of these cauteries with him to every operation. Finally, the pleasure to be derived from raking out an offending projection through the eystoscope under the direct control of the eye, together with the ease and simplicity with which this can be accomplished, will amply repay him for all his trouble.

600 Carleton Building.

\section{SOME NEW CAMERAS FOR LABORATORY USE *}

Louis B. Wilson, M.D., Rochester, MinN.

I have recently completed two cameras for laboratory use, and in describing them also include two others which have been in use for some time previously.

\section{CAMERA FOR USE WITH PROCTOSCOPE}

This camera (Fig. I) consists of a cylindrical barrel (A) to the front end of which is attached a rapid, short-focus, photographic lens $(B)$ and to the other end of which is attached a simple photographic shutter $(C)$ and small metal receiver $(D)$ for taking a plate-holder $(E)$ which carries an ordinary photographic plate $4.5 \mathrm{by} 6 \mathrm{~cm}$. in diameter.

In use, when a desirable field is found through the directvision proctoscope $(F)$, the camera is inserted with the shutter closed and set for time exposure and the dark slide of the plate-holder drawn. The patient's buttocks are steadied, the shutter snapped and an exposure of from 2 to 5 seconds given. The shutter is then closed and the camera withdrawn from the proctoscope. The operation should require not more than twenty seconds, and interferes but slightly with the ordinary course of a proctoscopic examination. The resulting pictures



Fig. 1.-Camela for use with proctoscope; $A$, tube; $B$, lens; $C$, shitter; $D$, receiver ; $E$, plate-holder ; $F$, proctoscope.

are circular and $1 \frac{118}{8}$ inch in diameter. The chief difficulty encountered is in maintaining the patient in a fixed position for the few seconds necessary to make an exposure.

\section{MINIATURE CAMERA FOR PHOTOMICROGRAPHY}

Laboratory workers have for a long time experienced great inconvenience in having to carry a microscopic slide from the

* From the Mayo Clinis. microscope which they ordinarily use to one set up and adjusted for photography. A number of eameras have been devised to obviate this difficulty. With but two exceptions, these have all required the use of a large heavy plate on which the microscope rests at ail times or to which it must be transferred after the desired field is found. Of the two exceptions, one is a camera which fits directly on the drawtube of the microscope, weighs $685 \mathrm{gm}$. ( 23 ounces) and uses a plate of a size difficult to obtain in America. The other is a camera which has a very heavy base, and while the whole apparatus may be moved up to the microscope, yet has no means of rapidy centering the two. The miniature camera here described and the larger portable camera to be described next both get rid of the inconvenience of the heavy sole-plate, and yet work with simplicity, speed and accuracy.

The miniature camera (Fig. 2 ) consists of a pyramidal aluminum box $(A)$ bearing at one end a shutter $(B)$ with a light-tight connecting sleeve $(C)$ and at the other end a receiver $(D)$ which takes a plate-holder $(E)$ carrying a plate of the ordinary block-note size, 4.5 by $6 \mathrm{~cm}$. The whole apparatus is 9 inches long and welghs, complete as it goes on the microscope, only a trifle over 7 ounces. In use, when a desirable field has been found in the microscope, the camera is slipped on the microscope, to which it fits securely by

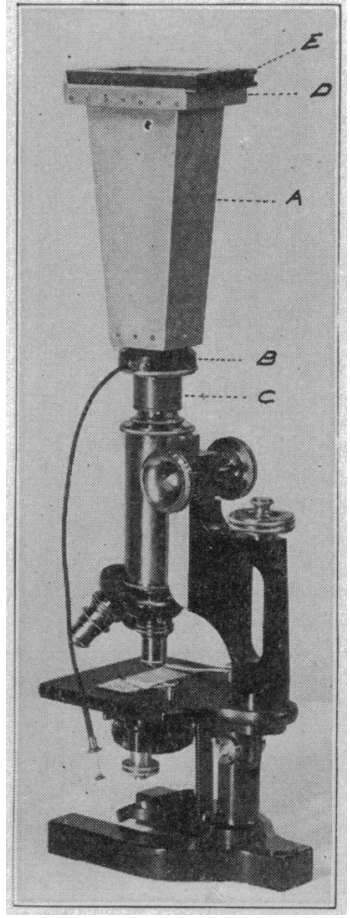
era for photomicrography:
$A$, box ; $B$, shutter; $C$, lighttight sleeve: $D$, receiver
Fig. 2.- Miniature cam $E$, plate-holder.

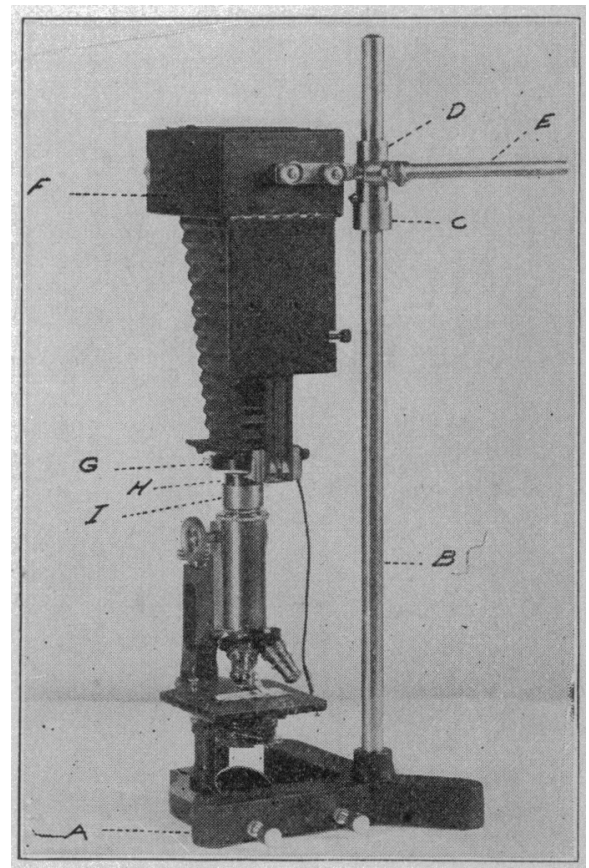

Fig. 3.- Poltable stand and camera for photomicrography; $A$, base ; $B$ support; $C$, collar; $D$, reducing clamp; $E$, arm ; $F$, cámera ; $Q$, shutter $; H$, and $I$, sleeve. means of a sleeve that remains permanently on the drawtube. The camera is placed in position with the dark slide drawn and the shutter set for a time exposure and closed. The focus is then adjusted an amount previously determined by the fine adjustment screw, the shutter opened and the exposure made. The shutter is then closed and the camera removed from the micrcscope. The whole operation may be done without in the least jarring the microscope. Aside from the time of the exposure, which of course varies with the kind of light used and the magnification, the entire process requires less than a minute. This litt!e camera gives excellent results, though its field of usefulness is, of course, limited by the small size of the plate and by the short range $o_{-}^{s}$ magnification resulting from its short, fixed extension.

\section{MEDIUM-SIZED PORTABLE STAXD AND CAMERA FOR} PHOTOMICROGRAPHY

This stand and camera (Fig. 3) have been devised to get rid of the inconvenience of the sole-plate or other special stand to which the microscope has hitherto been attached when used for photomicrography. The new features in it are: (I) a tripod base ( $A$ ) which can be adjusted accurately by 